\title{
CLONAGEM E EXPRESSÃO DO GENE DA GLICOPROTEÍNA S1 DO VÍRUS DA BRONQUITE INFECCIOSA DAS GALINHAS EM PICHIA PASTORIS
}

\author{
M.C.M. Gonçalves, A.M. Gibertoni, M.F.S. Montassier, C.C. Fernandes, H.J. Montassier
}

Universidade Estadual Paulista, Faculdade de Ciências Agrárias e Veterinárias, Departamento de Patologia Veterinária, Laboratório de Imunologia e Virologia, Rod. Prof. Paulo D. Castellane, s/nº, CEP 14884-900, Jaboticabal, SP, Brasil.

\section{RESUMO}

\begin{abstract}
Variações genética e antigênica são observadas com frequência elevada entre estirpes do VBIG e envolvem principalmente a glicoproteína S1. Com o objetivo de contribuir com a disponibilidade de ferramentas para o imunodiagnóstico e a imunoprofilaxia da bronquite infecciosa das galinhas foi desenvolvida uma metodologia para expressão recombinante da glicoproteína S1 na levedura Picchia pastoris. O cDNA do gene codificador dessa proteína foi obtido a partir de RNA viral de ovos embrionados infectados com a estirpe M41 do VBIG submetido à transcrição reversa (RT) e reação em cadeia da polimerase (PCR), amplificando-se a sequência codificadora de S1 acrescida de extremidades compatíveis com a clonagem no vetor usado na transformação de leveduras. A indução com metanol resultou na produção de uma proteína detectada como banda única do tamanho previsto, em western-blot, no lisado celular das leveduras transformadas. A expressão em P. pastoris mostrou ser um método eficaz para a produção recombinante da proteína S1 do VBIG, com potencial para utilização em técnicas de imunodiagnóstico da bronquite infecciosa das galinhas.
\end{abstract}

PALAVRAS-CHAVE: VBIG, glicoproteína S1, proteína da espícula, Pichia pastoris.

\section{ABSTRACT}

CLONING AND EXPRESSION IN PICHIA PASTORIS OF THE S1 GLYCOPROTEIN GENE OF THE CHICKEN INFECTIOUS BRONCHITIS VIRUS. Genetic and antigenic variation are very frequently observed among IBV strains and affect mainly the S1 glycoprotein. In order to contribute to the availability of tools for immunodiagnosis and immunoprophylaxis of chicken infectious bronchitis we developed an expression system for production of recombinant S1 glycoprotein in Pichia pastoris. We obtained the cDNA from viral RNA on embryonated eggs infected with the M41 strain of IBV, by reverse transcription (RT) and polymerase chain reaction (PCR), amplifying the S1 coding sequence with extremities compatible with the vector used to transform yeast. Induction with methanol led to the production of a protein with the predicted molecular weight that was detected by Western blot in the cell lysate of transformed yeast. Expression in $P$. pastoris proved to be an effective method for recombinant production of S1 protein from IBV, with potential for use in immuno-diagnosis of chicken infectious bronchitis virus.

KEY WORDS: IBV, S1 glycoprotein, spike protein, Pichia pastoris.

\section{INTRODUÇÃO}

A levedura Pichia pastoris constitui um dos sistemas mais utilizados e bem sucedidos para a expressão heteróloga de proteínas, seja para emprego em pesquisa, seja para produção industrial. Uma característica marcante dessa levedura é o fato dela combinar a capacidade de crescer a altas densidades celulares em meio mínimo, com a capacidade de secretar proteínas heterólogas eficientemente, com pequena secreção de proteínas endógenas (RESINA et al., 2005). Além disso, essa levedura é capaz de processar a maioria das modificações pó-traducionais incluindo processamento proteolítico e glicosilação, conservando características antigênicas das proteínas originais, o que facilita sua aplicação em ensaios diagnósticos e em vacinas de subunidade. (CEREGHINO; CREGG, 2000).

P. pastoris já foi usada eficientemente para a produção de diversas proteínas virais como a glicoproteína D do Herpesvírus Bovino I (ZHu et al., 1999), o antígeno nuclear dos vírus das hepatites $B$ e C (WATElet et al., 2002; Rivero et al., 2002), a proteína Gag do vírus da Imunodeficiência Humana tipo 1 (HIV-1) (JIANG et al., 2005), a glicoproteína de envelope do vírus da dengue tipo 2 (WEI et al., 2003) 
e a proteína VP2 do vírus da doença infecciosa da bursa (Wu et al., 2005).

A proteína S1 do Vírus da Bronquite Infecciosa das Galinhas (VBIG) é a principal indutora da resposta imune protetora contra a infecção e é um dos principais antígenos alvo de testes de imunodiagnóstico para identificaçãoe caracterização de isolados (Косн et al., 1990). Já foram produzidas preparações recombinantes da proteína S1 utilizando batatas transgênicas (ZHOU et al., 2003), adenovírus (JoHNSON et al., 2003), baculovírus (Song et al., 1998) e poxvírus (WANG et al., 2002).

Em vista da importância do VBIG em sanidade avícola e da carência de meios rápidos, precisos e acessíveis de diagnóstico laboratorial da infecção, propôs-se a expressão da proteína $\mathrm{S} 1 \mathrm{em}$ P. pastoris, que pode constituir uma alternativa interessante para a produção desse antígeno. Oobjetivo deste trabalho foi expressar o gene da proteína de superfície S1 da estirpe M41 do VBIG em um sistema de levedura $P$. pastoris, para emprego como antígeno no imunodiagnóstico da bronquite infecciosa das galinhas.

\section{MATERIAL E MÉTODOS}

\section{Propagação viral}

A estirpe M41 do VBIG (2 ${ }^{\mathrm{a}}$ passagem de 25/6/2007, gentilmente cedido pelo Centro $\mathrm{Na}$ cional de Pesquisa de Suínos e Aves, CNPSA da EMBRAPA, Concórdia, SC, Brasil) foi propagada na cavidade alantoide de ovos embrionados, livres de patógenos específicos (SPF) (fornecidos por Merial Saúde Animal com 1 dia de incubação), através do protocolo recomendado por GELB (1998). Após 36 horas da inoculação, os ovos foram resfriados a $4^{\circ}$ C por, no mínimo, 4 horas e o líquido alantoide foi colhido e centrifugado a $3.000 \mathrm{~g}, 4^{\circ} \mathrm{C}$ por $10 \mathrm{~min}$, para clarificação, sendo armazenado a $-70^{\circ} \mathrm{C}$ até o momento do uso.

\section{Clonagem do gene da proteína S1}

O RNA total da estirpe M41 presente no líquido alantoide clarificado foi extraído com o reagente Trizol LS (Invitrogen, Carlsbad, CA, USA), de acordo com as recomendações do fabricante. Para a obtenção da open reading frame (orf) correspondente a S1 na transcrição reversa (RT) e na reação da polimerase em cadeia (PCR), foram projetados os oligonucleotídeos iniciadores de sentido positivo (5'-CACGTGATGTTGGTAACACCTCTTTT-3') e negativo (5'-CCGCGGAGAACGTCTAAAACGACG-3'), com base na sequência da estirpe M41 (GenBank $\mathrm{n}^{\circ}$ de acesso-M21883), com a adição de sequências de sítios de restrição nos seis nucleotídios $5^{\prime}$ terminais.
O gene foi amplificado a partir do cDNA obtido na RT , utilizando-se os primers acima e a enzima "Platinum Taq DNA Polymerase - High Fidelity" (Invitrogen, Carlsbad, CA, USA) no termociclador LightCycler (BIO-RAD, Hercules, CA, USA), com o seguinte perfil térmico: $95^{\circ} \mathrm{C}$ por 5 minutos; 30 ciclos de $94^{\circ} \mathrm{C}$ por 1 minuto, $56^{\circ} \mathrm{C}$ por 1 minuto e $72^{\circ} \mathrm{C}$ por 2 minutos; seguido de $72^{\circ} \mathrm{C}$ por $10 \mathrm{minu}-$ tos. O produto amplificado no tamanho esperado $(1.613 \mathrm{pb})$ foi separado por eletroforese em gel de agarose (1\% em tampão TBE 0,5\%), purificado com "GFX PCR DNA and Gel Band Purification Kit" (GE Healthcare Life Sciences, Piscataway, NJ, USA), de acordo com as instruções do fabricante, e clonado no vetor pGEM-T Easy (Promega Corporation, Madison, WI, USA), que foi usado para a transformação de Escherichia coli da linhagem DH10b, sendo os transformantes cultivados em meio LB (1\% Triptona, 0,5\% Extrato de levedura, $1 \% \mathrm{NaCl}$ ) com $50 \mu \mathrm{g} / \mathrm{mL}$ de ampicilina e glicerol $40 \%$. Preparações de DNA plasmidial obtidas a partir dos clones transformantes foram digeridas com as enzimas PmL I e Sac II, para verificação da presença de plasmídeos contendo o inserto do gene S1. O inserto clonado foi isolado através de digestão com as mesmas enzimas, eligado ao vetor $\mathrm{pFLD} \alpha$ (Invitrogen, Carlsbad, CA, USA) usado para clonagem de E. coli da linhagem $\mathrm{DH} 10 b$. Os clones foram submetidos ao sequenciamento, utilizando "Big Dye Terminators" (Perkin Elmer), para confirmar a identidade do produto clonado a ser posteriormente inserido no vetor de expressão.O plasmídeo recombinante obtido foi linearizado com a enzima ClaI (New England BioLabs, Ipswich, MA, USA) eutilizado para transformação de Pichia pastoris linhagem GS115 por eletroporação no Gene Pulse II (Bio Rad, Hercules, CA, USA) com posterior seleção dos transformantes em meio YPD sólido (Yeast extract, Peptone, Dextrose Médium - $1 \%$ extrato de levedura, $2 \%$ peptona, $2 \%$ glicose, $2 \%$ ágar) com 100 $\mathrm{mg} / \mathrm{mL}$ de zeocina.

\section{Expressão recombinante da proteína $\mathrm{S} 1 \mathrm{em}$ Pichia pastoris}

Todos os cultivos foram feitos sob agitação orbital a $250 \mathrm{rpm}, 30^{\circ} \mathrm{C}$ e iniciados com um pré-inóculo em $5 \mathrm{~mL}$ de YPD (Yeast extract, Peptone, Dextrose Medium - 1\% extrato de levedura, 2\% peptona, 2\% glicose) cultivado por 16-18 horas.

O inóculo foi centrifugado e as células ressuspendidas em meio mínimo (Minimal Ammonium Sulfate Medium - 1,34\% Yeast Nitrogen Base without amino acids, 0,02\% Biotina, 1\% Sulfato de amônio, 0, 004\% Histidina) suplementado com glicerol 2\% (MGA Minimal Glicerol with Ammonium Sulfate Medium), no qual permaneceram sob agitação por 36 horas. A indução da expressão deu-se após a centrifuga- 
ção e ressuspensão da cultura em meio mínimo suplementado com metanol 1\% (MMA - Minimal Methanol with Ammonium Sulfate Medium) no qual permaneceram sob agitação por 96 horas com adição de $1 \%$ de metanol a cada 24 horas.

\section{Separação das proteínas da levedura recom- binante}

As culturas foram centrifugadas por 3 minutos a $14.000 \mathrm{~g}$ para separar o sobrenadante das células.

Para a extração da proteína celular total as células foram ressuspendidas em tampão de lise $(50 \mathrm{mM}$ fosfato de sódio monobásico, pH7,4,1 mMEDTA, 5\% glicerol, $1 \mathrm{mM}$ fluoreto de fenilmetilsulfonila-PMSF) e centrifugadas a $3.000 \mathrm{~g}, 4^{\circ} \mathrm{C}$ por 10 minutos. As células foram novamente ressuspendidas em $2 \mathrm{~mL}$ de tampão de lise e foi adicionado igual volume de "glass beads acid-washed 425-600 $\mu \mathrm{M}$ " (Sigma-Aldrich Corp., St. Louis, MO, USA) em tubos tipo falcon de $15 \mathrm{~mL}$. A suspensão foi agitada em vortex por 60 minutos, alternando-se um minuto em vortex e um minuto no gelo. A lise foi sucedida de centrifugação a $12.000 \mathrm{~g}, 4^{\circ} \mathrm{C}, 10$ minutos. O sobrenadante colhido foi submetido a eletroforese em gel de poliacrilamida na presença de SDS e western-blot.

As proteínas secretadas no sobrenadante da cultura foram concentradas com polietileno glicol (PEG) 8.000 e $\mathrm{NaCl}$. O volume do sobrenadante foi medido e, sob agitação suave foi adicionado 2,7\% do volume em massa de $\mathrm{NaCl}$ e 8,7\% de PEG 8.000. Após dissolução completa do PEG e do $\mathrm{NaCl}$ o sobrenadante permaneceu sob agitação por $1 \mathrm{~h} \mathrm{a} 4^{\circ} \mathrm{C}$ e em geladeira por 16-18 horas. As proteínas foram sedimentadas por centrifugação a $10.000 \mathrm{~g}$, por 30 minutos e a $4^{\circ}$ C. O sedimento formado foi ressuspendido em 200 $\mu \mathrm{L}$ de tampão TEN $(0,1 \mathrm{M} \mathrm{NaCl}, 10 \mathrm{mM}$ Tris- $\mathrm{HCl} \mathrm{pH}$ 8,0, 1 mM EDTA pH 8,0) pH 7,4 adicionado de 25 $\mu \mathrm{L}$ do inibidor de protease PMSF $10 \mathrm{mM}$.

As proteínas obtidas do lisado celular e do sobrenadante concentrado da cultura foram quantificadas (BRADFORD,1976).

Análise da Proteína S1 Expressa por Eletroforese em gel de poliacrilamida SDS e western-blot

A eletroforese em gel de poliacrilamida (SDSPAGE) foi realizada aos pares, em géis de separaçãoa 9\% (LAEMMLI, 1970). As bandas foram detectadas, em um dos géis, por meio da coloração com Coomassie Blue (HARLOW; LANE, 1988) e os polipeptídeos do outro gel foram eletrotransferidos em cuba úmida para uma membrana de PVDF (GE Healthcare Life Sciences, Piscataway, NJ, USA). A membrana foi submetida a lavagens com água deionizada, bloqueada com 10 $\mathrm{mL}$ de PBS (Salina tamponada com fosfato: 0,01 M tampão fosfato; 2,7 mM KCl; 137 mM NaCl; pH 7,4);
5\% deleite em pó desnatado(LPD) e 0,02\% Tween-20, sob agitação suave por uma hora, a temperatura ambiente (TowBIN et al., 1979) einicialmente incubada com anticorpo monoclonal antipoli-histidina (GE Healthcare Life Sciences, Piscataway, NJ, USA) na diluição 1:500 em tampão PBS 0,01M contendo 5\% LPD e 0,02\% Tween-20, sob por uma hora e lavada com PBS e PBST (Salina tamponada com fosfato + $1 \%$ Tween). $\mathrm{O}$ anticorpo conjugado com peroxidase (coelho anti-IgG de camundongo) (GE Healthcare Life Sciences, Piscataway, NJ, USA) na diluição 1:500 em PBS-LPD 5\% foi utilizado para revelar a interação antígeno-monoclonal por incubação durante uma hora. Na reação com soro policlonal, a membrana foi incubada com um pool de soros de aves de postura com 20 semanas de idade e que haviam recebido quatro imunizações com a vacina atenuada da estirpe H120 do VBI na diluição 1:100 durante 12 horas e após as lavagens foi adicionado o anticorpo conjugado anti-IgG de galinha com a peroxidase (Bethyl Laboratories, Montgomery, TX), na diluição 1:200 em PBST, permanecendo sob agitação por mais 12 horas. As membranas foram novamente lavadas com PBS e PBST e o desenvolvimento da cor foi obtido após a adição da mistura do cromógeno e substrato contendo dietil-amino-etil-benzidina $(0,7 \mathrm{mg})$ e peróxido de hidrogênio - uréia $(1,6 \mathrm{mg})$ (FAST DAB; Sigma-Aldrich, St. Louis, MO, USA), sendo a reação de coloração interrompida por meio de lavagem com água deionizada. As membranas foram dessecadas em temperatura ambiente e conservadas em local escuro.

\section{RESULTADOS E DISCUSSÃO}

Uma limitação importante para tornar disponível reagentes para testes sorológicos aplicados ao diagnóstico de patógenos como o VBIG é a necessidade de preparações purificadas de vírus, o que requer a propagação em grandes volumes de líquido alantoide e o processamento do antígeno por técnicas demoradas, trabalhosas e muito onerosas, como ultracentrifugação em gradientes (LoA et al., 2004).

A expressão de genes clonados constitui um importante método de preparo de grandes quantidades de antígenos virais altamente purificados. Há possibilidade de usar vários sistemas de expressão baseados em vetores plasmidiais tanto em procariotos, como E. coli, quanto em eucariotos como leveduras acrescendo-se, ainda, a possibilidade de serem usados vetores virais derivados de Poxvírus ou Baculovírus, replicados em células de mamíferos ou de insetos. (CHEN et al., 2000).

A clonagem do gene da proteína S1 do VBIG no sistema pFLD $\alpha-P$. pastoris foi realizada com a utilização de iniciadores específicos para as sequências 
de nucleotídeos flaqueando as regiões $5^{\prime}$ e $3^{\prime}$ da orf do gene S1 da estirpe M41 permitindo a obtenção de todo o segmento gênico codificador no tamanho esperado de 1613 pb (Fig. 1).

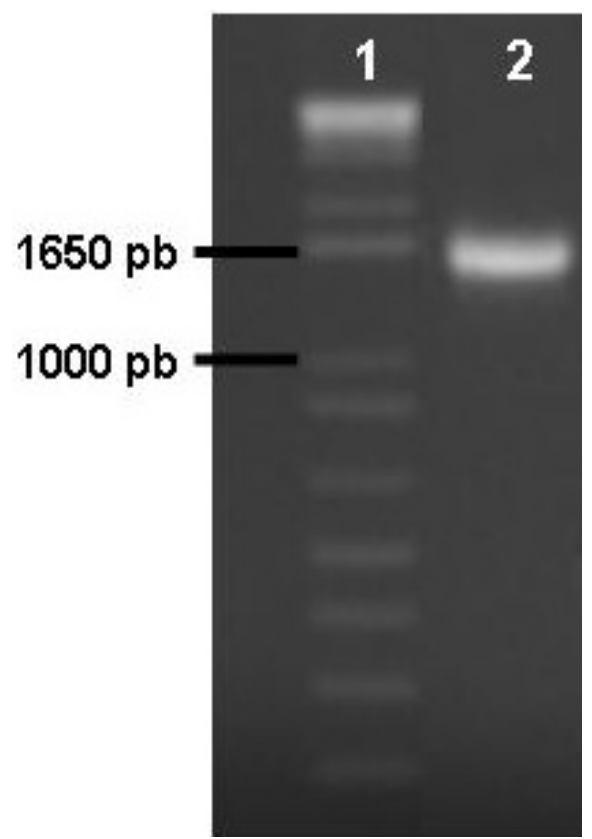

Fig. 1 - Eletrofotograma do produto amplificado, com os iniciadores específicos para S1, e purificado. (1) TM tamanho molecular : '1kb Plus DNA ladder' (Invitrogen, Carlsbad, CA. USA), (2)Segmento amplificado do gene da glicoproteína S1.

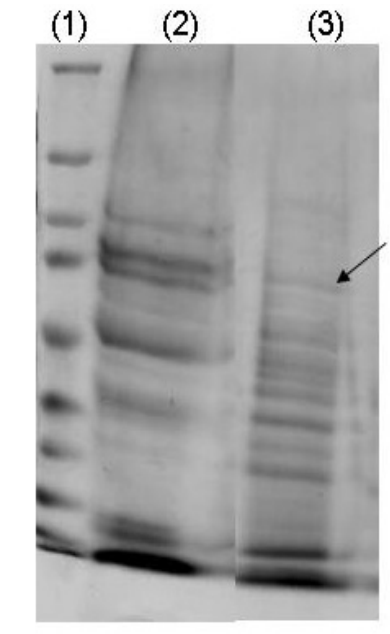

A
O sequenciamento do inserto de clones transformantes de E. coli com as construções em pFLD $\alpha$ (Invitrogen, Carlsbad, CA, USA) revelou identidade total com aquela do gene S1 da estirpe M41 do VBIG disponível no GenBank sob número de acesso M21883 (dados não mostrados). Uma destas preparações de DNA plasmidial foi linearizada e usada na transformação de P. pastoris e entre os clones transformantes da levedura um foi escolhido para ser submetido à indução com metanol.

A análise por SDS-PAGE do extrato celular da cultura induzida mostrou a presença de uma banda com peso molecular estimado em $90 \mathrm{kDa}$, juntamente com várias proteínas da levedura. $\mathrm{O}$ western-blot revelou uma única banda marcada pelos anticorpos monoclonais antipoli-histidina no tamanhoesperado, fornecendo evidência de expressão recombinante da proteína S1 em fusão com a cauda de poli-histidina, conforme mostrado na Figura 2. A reação com soro de aves de postura contendo anticorpos policlonais contra o VBIG evidenciou que a proteína S1 expressa no sistema recombinante apresenta epítopos em comum com a proteína S1 do próprio VBIG, apesar da presença de outras bandas dadas por reações inespecíficas a proteínas do extrato celular da levedura, visto que o material não foi submetido a purificação. O tamanho molecular observado é compatível com o da glicoproteínaS1 contendoa cauda de poli-histidina, pois há aminoácidos adicionais junto à extremidade C-terminal acarretando massa molecular ligeiramente maior que a descrita para a proteína nativa do VBIG (Cavanagh, 1983).

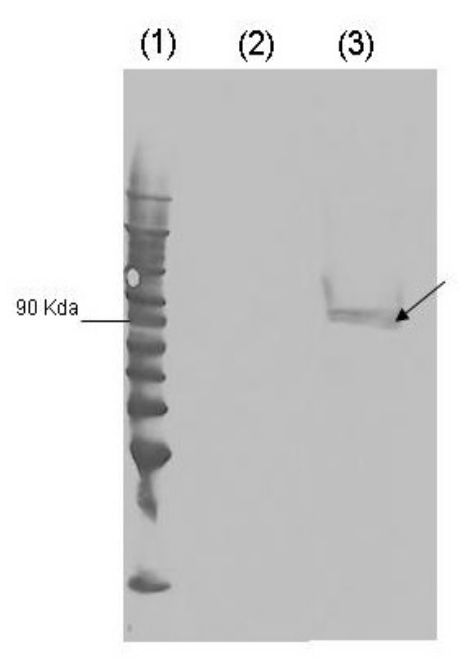

B

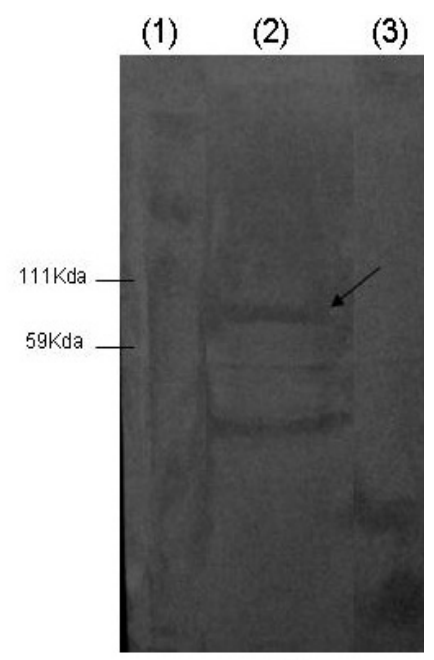

C

Fig. 2 - Proteínas em lisado de Pichia pastoris transformadas com pFLDaS1 e em concentrado de Líquido Cório Alantoide infectado com a estirpe M41 do VBIG (A) SDS-PAGE: coloração Coomassie blue ; (B) western-blot com anticorpo anti-His (GE Healthcare Life Sciences, Piscataway, NJ, USA). Canaletas: (1) Marcador de peso molecular (Invitrogen, Carlsbad, CA. USA), (2) Concentrado de Liquido Cório Alantoide infectado com VBIG M41, (3) Extrato celular da linhagem recombinante após 96 horas de indução com metanol; (C) western-blot com soro policlonal de aves vacinadas com VBIG. Canaletas: (1) Marcador de peso molecular (Bio Rad, Hercules, CA. USA), (2) Lisado celular da linhagem recombinante após 96 horas de indução com metanol, (3) Extrato celular de Pichia pastoris não transformada com pFLDa (Invitrogen, Carlsbad, CA. USA). 


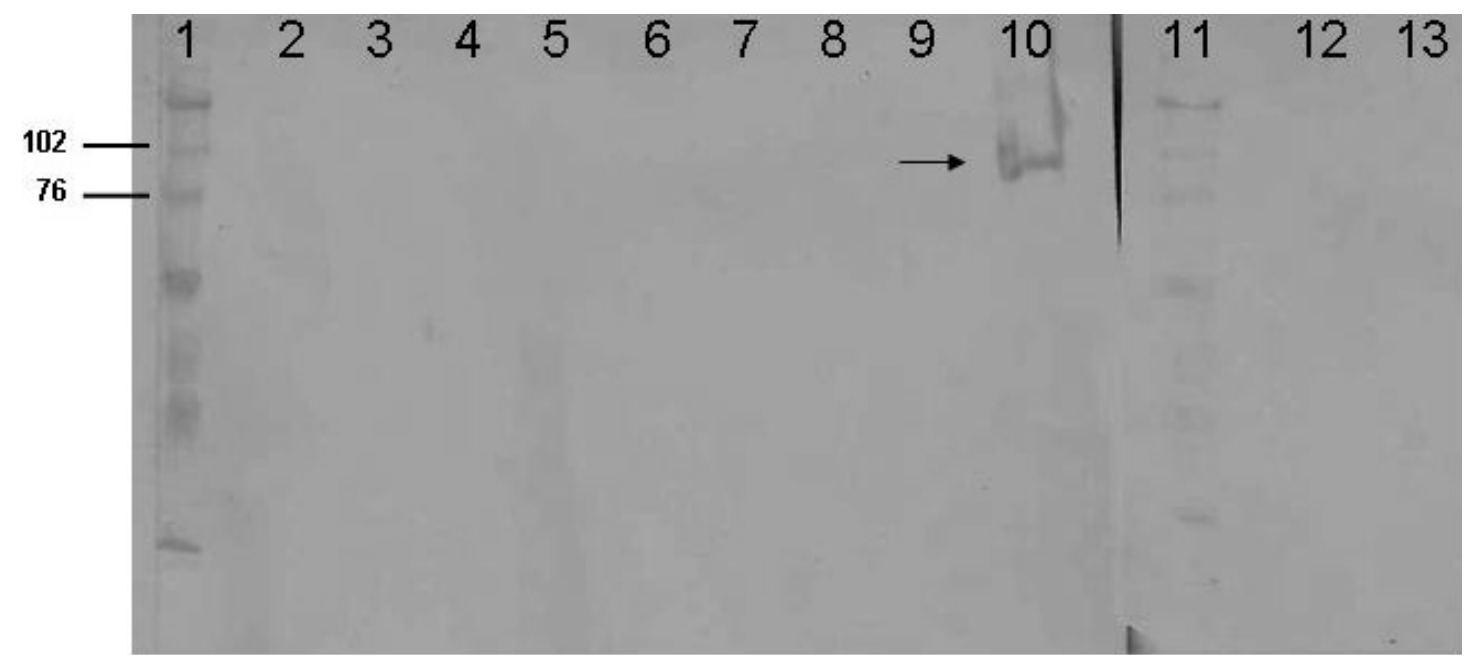

Fig. 3 - Cinética de produção recombinante da proteína S1, no lisado celular, por células de um clone transformante de Pichia pastoris com pLDaS1 com detecção por western-blot utilizando anticorpo anti-His (GE Healthcare Life Sciences, Piscataway, NJ, USA). Canaletas (1) Marcador de peso molecular (Bio Rad, Hercules, CA. USA), (2) 6h indução, (3) 12h, (4) 24h, (5) 36h, (6) 48h, (7) 60h, (8) 72h, (9) 84h, (10) 96h, (11) Marcador de peso molecular, (12) 108h de indução, (13) $120 \mathrm{~h}$ de indução.

Durante a otimização do procedimento de expressão foram realizadas coletas de proteína da fração celular e da fração secretada, a 24h, 48h, 72h, 96h, $108 \mathrm{~h}$ e $120 \mathrm{~h}$ de indução para analisar a cinética da secreção da proteína expressa. Os extratos obtidos nesses tempos de indução foram submetidos a SDSPAGE e western-blot, verificando-se que somente o lisado celular a 96h de indução apresentou a banda proteíca do tamanho esperado (aproximadamente $90 \mathrm{kDa}$ ), detectada por anticorpo monoclonal antipolihistidina (Fig. 3).

O sistema adotado nesse estudo é indicado para a expressão recombinante da proteína secretada no sobrenadante das culturas, mas a proteína S1 não foi detectada sob essa forma, nem nas culturas em pequeno volume com meio mínimo, nem em meio rico BMY (Buffered complex medium with histidine - $1 \%$ yeast extract, $2 \%$ peptone, $100 \mathrm{mM}$ phosphate buffer pH 6,0; 1,34\% Yeast Nitrogen Base without amino acids, 0,02\% Biotina, 1\% Ammonium sulfate, 0,004\% Histidine) suplementado com glicerol 1\% (BMGY-Buffered glycerol complex médium with histidine) e posteriormente com metanol 1\% (BMMY - Buffered methanol complex médium with histidine) no qual a quantidade de biomassa produzida foi superior (dados não mostrados). Pode-se supor que o nível de expressão em meio mínimo não tenha sido suficiente para a produção de quantidade detectável da proteína no sobrenadante, $\mathrm{o}$ que tornaria necessário o cultivo em volumes maiores. Por outro lado, a expressão de proteína em frascos incubados sob agitação orbital apresenta limitações de volume, o que compromete a transferência de oxigênio, que, por sua vez, interfere no consumo de metanole,consequentementenaindução da expressão (Khatri; Hoffman, 2005; Zhang et al., 2000).
A ausência de detecção da proteína S1 no sobrenadante pode ter decorrido de outro problema associado à expressão heteróloga de proteínas que é a retenção de parte do produto no interior das células, o que já foi verificado no caso da lipase de Rhizopus oryzae (Resina et al., 2005), do tripsinogênio humano (GASSER et al., 2007) e de fragmentos de anticorpos scFv (GASSER et al., 2006). O fenômeno pode ser explicado pelo elevado estresse celular a que são submetidas as leveduras, quando uma alta expressão de polipeptídeos não é acompanhada de uma taxa de processamento equivalente, o que forçaria as proteínas a ficarem retidas no meio intracelular (GASSER et al., 2006). Essa resposta é denominada UPR (Unfolded Protein Response) e foi descrita para P. pastoris por HoHENBLum et al. (2004) na expressão de tripsinogênio. Uma consequência potencial dessas limitações de processamento é a resposta de estresse chamada ERAD (Endoplasmic Reticulum-Associated Protein Degradation) (MatTANovich et al., 2004). WerNER et al. (1996) e HiLLER et al. (1996) mostraram que na ERAD os substratos retrotransportados para o citosol são conjugados com ubiquitina e destinados a degradação.

A despeito da proteína recombinante ter sido obtida somente no extrato celular e não ter sido secretada, conforme se esperava para a expressão a partir do vetor $\mathrm{pFLD} \alpha$ (Invitrogen, Carlsbad, CA, USA), sua detecção no western-blot permite prever o seu potencial de aplicação como antígeno principalmente em ensaios imunoenzimáticos.

Concluindo, a proteína S1 da estirpe M41 do VBIG foi expressa eficientemente no lisado celular de Picchia pastoris a partir de construções em pFLD $\alpha$ (Invitrogen, Carlsbad, CA, USA) e pode ser futura- 
mente utilizada em técnicas de imunodiagnóstico da infecção pelo VBIG.

\section{AGRADECIMENTOS}

À Fundação de Amparo à Pesquisa de São Paulo, financiadora deste projeto (Processo número 01/14650-3), ao Conselho Nacional de Pesquisa CNPq (proc. 477140/2003-3) e à Empresa MERIAL Saúde Animal.

\section{REFERÊNCIAS}

BRADFORD, M.M. A rapid and sensitive method for the quantitation of microgram quantities of protein utilizing the principle of protein-dye binding. Analytical Biochemistry, v.72, n.1/2, p.248-254, 1976.

CAVANAGH, D. Coronavirus IBV: Structural Characterization of the spike protein. Journal of General Virology, v.64, n.12, p.2577-2583, 1983.

CEREGHINO, J.L.; CREGG, J.M. Heterologous protein expression in the methylotrophic yeast Pichia pastoris. FEMS Microbiology, v.24, p.45-66, 2000.

CHEN, C.M.; CHENG, W.T.K.; CHANG, Y.C.; CHANG, T.J.; CHEN, H.L. Growth enhancement of fowls by dietary administration of recombinant yeast cultures containing enriched growth hormone. Life Sciences, v.67, p.2103-2115, 2000.

GASSER, B.; MAURER, M.; GACH, J.; KUNERT, R.; MATTANOVICH, D. Engineering of Pichia pastoris for improved production of antibody fragments. Biotechnology and Bioengineering, v.94, n.2, p.353-361, 2006.

GASSER, B.; MAURER, M.; RAUTIO, J.; SAUER, M.; BHATTACHARYYA, A.; SALOHEIMO, M.; PENTTILA, M.; MATTANOVICH, D. Monitoring of transcriptional regulation in Pichia pastoris under protein production conditions. BMC Genomics, v.8, p.179, 2007.

GELB JUNIOR, J. Infectious bronchitis, In: PURCHASE, H.G.; ARP, L.H.; DOMERMUTH, C.H.; PEARSON, J.E. (Ed.) A laboratory manual for the isolation and identification of avian pathogens. 3.ed. Kennett: American Association of Avian Pathologists, 1998. p.124-127.

HARLOW, E.; LANE, D. Antibodies: a laboratory manual. New York: Cold Spring Harbor Laboratory, 1988. 865 p.

HILLER, M.M.; FINGER, A.; SCHWEIGER, M.; WOLF, D.H. ER degradation of a misfolded luminal protein by the cytosolic ubiquitin-proteoasome pathway. Science, v.273, p.1725-1758, 1996.
HOHENBLUM, H.; GASSER, B.; MAURER, M.; BORTH, N.; MATTNOVICH, D. Effects of gene dosage, promoter, and substrates on unfolded protein stress of recombinant Pichia pastoris. Biotechnology and Bioengineering, v.85, n.4, p.367-375, 2004.

JIANG, W.Z.; JIN, N.Y.; LI, Z. J.; ZHANG, L.S.; WANG, H.W.; ZHANG, Y.J.; HAN, W.Y. Expression and characterization of Gag protein of HIV-1 CN in Pichia pastoris. Journal of Virological Methods, v.123, p.35-40, 2005.

JOHNSON, M.A.; POOLEY, C.; IGNJATOVIC, J.; TYACK, S.G. A recombinant fowl adenovirus expressing the $\mathrm{S} 1$ gene of infectious bronchitis virus protects against challenge with infectious bronchitis virus. Vaccine, v.21, p.2730-2736, 2003.

KHATRI, N.K.; HOFFMAN, F. Impact of methanol concentration on secreted protein production in oxygen-limited cultures of recombinant Pichia pastoris. Biotechnology and Bioengineering, v.93, n.5, p.871-879, 2005

KOCH, G.; HARTOG, L.; KANT, A.; ROOZELAAR, D.J. Antigenic domains on the peplomer protein of avian infectious bronchitis virus: correlation with biologic functions. Journal of General Virology, v.71, p.1929-1935, 1990.

LAEMMLI, Cleavage of structural proteins during assembly of head of bacteriophage T4, Proceedings of the National Academy of Science, v.81, p.2708-2712, 1970.

LOA, C.C.; LIN, T.L.; WU, C.C.; BRYAN, T.A.; HOOPER, T.; SCHRADER, D. Expression and purification of turkey coronavirus nucleocapsid protein in Escherichia coli. Journal of Virological Methods, v.116, p.161-167, 2004.

MATTANOVICH, D.; GASSER, B.; HOHENBLUM, H.; SAUER, M. Stress in recombinant protein producing yeasts. Journal of Biotechnology, v.113, p.121-135, 2004.

RESINA, D.; COS, O.; FERRER, P.; VALERO, F. Developing high cell density fed-batch cultivation strategies for heterologous protein production in Pichia pastoris using the nitrogen source-regulated FLD1 promoter. Biotechnology and Bioengineering, v.91, n.6, p.760-767, 2005.

RIVERO, N.A.; MUSACCHIO, A.; LORENZO, L.; ALVARES, C.; MORALES, J. Processing of the hepatitis $C$ virus precursor protein expressed in the methylotrophic yeast Pichia pastoris. Biochemical and Biophysical Research Communications, v.295, p.81-84, 2002.

SONG, C.S.; LEE, Y.J.; LEE, C.W.; SUNG, H.W.; KIM, J.H.; MO, J.P.; IZUMIYA, Y.; JANG, H.K.; MIKAMI, $\mathrm{T}$. Induction of protective immunity in chickens vaccinated with infectious bronchitis virus S1 glycoprotein expressed by a recombinant baculovirus. Journal of General Virology, v.79, p.719-723, 1998. 
TOWBIN, H.; STAEHETIN, T.; GORDON, J. Eletrophoretic transfer of protein from polyacrylamide gels to nitrocellulose sheets: Produce and some applications. Proceedings of the National Academy of Science of the USA, v.76, p.4350-4354, 1979.

WANG, X.; SCHNITZLEIN, W.M.; TRIPATHY, D.N.; GIRSHICK, T.; KHAN, M.I. Construction and immunogenicity studies of recombinant fowl poxvirus containing the $\mathrm{S} 1$ gene of Massachusetts 41 strain of infectious bronchitis virus. Avian Diseases, v.46, n.4, p.831-838, 2002.

WATELET, B.; QUIBRIAC, C.M.; ROLLAND, D.; GERVASEI, G.; GAUTHIER, M.; JOLIVET, M.; LETOURNEUR, O. Characterization and diagnostic potential of hepatitis B virus nucleocapsid expressed in E. coli and $P$. pastoris. Journal of Virological Methods, v.99, p.99-114, 2002.

WEI, H.Y; JIANG, L.F.; XUE, Y.H.; FANG, D.Y.; GUO, H.Y. Secreted expression of dengue vírus type 2 fulllength envelope glycoprotein in Pichia pastoris. Journal of Virological Methods, v.109, p.17-23, 2003.

WERNER, E.D.; BRODSKY, J.L.; McCRACKEN, A.A. Proteasome-dependent endoplasmatic reticulum-associated protein degradation: An unconventional route to a familiar fate. Proceedings of the National Academy of Sciences of the USA, v.93, p.13797-13801, 1996.
WU, P.C.; SU, H.Y.; LEE, L.H.; LIN, D.T.; YEN, P.C.; LIU, H.J. Secreted expression of the VP2 protein of very virulent infectious bursal disease virus in the methylotrophic yeast Pichia pastoris. Journal of Virological Methods, v.123, p.221-225, 2005.

ZHANG, W.; BEVINS, M.A.; PLANTZ, B.A.; SMITH, L.A.; MEAGHER, M.M. Modeling Pichia pastoris growth on methanol and optimizing the production of a recombinant protein, the heavy-chain fragment $\mathrm{C}$ of botulinum neurotoxin, Serotype A. Biotechnology and Bioengineering, v.70, n.1, p1-8, 2000.

ZHOU, J.Y.; WU, J.X.; CHENG, L.Q.; ZHENG, W.J.; GONG, H.; SHANG, S.B.; ZHOU, E.M. Expression of immunogenic S1 glycoprotein of infectious bronchitis vírus in transgenic potatoes. Journal of Virology, v.77, n.16, p.9090-9093, 2003.

ZHU, X.; WU, S.; LETCHWORTH, G.J. A chimeric protein comprised of bovine herpesvirus type 1 glucoprotein D and bovine interlukin-6 is secreted by yeast and possesses biological activities of both molecules. Vaccine, v.17, p.269-282, 1999.

Recebido em 25/2/09

Aceito em 13/8/10 